\title{
Succeeding through Disruption: Exploring the Factors Influencing the Adoption of Disruptive Technologies in the Mobile Telecommunications Industry in Zimbabwe
}

\author{
Africa Makasi \\ PhD student, University of KwaZulu-Natal, South Africa and Harare Institute of Technology, Zimbabwe \\ africa.amaksi@yahoo.com \\ Krishna Govender \\ University of KwaZulu-Natal, South Africa and Regenesys Business School, South Africa \\ Lloyd Tapfuma
}

Women's University in Africa (MBA student). Africa Makasi. Harare Institute of Technology. Department of Technopreneurship, Zimbabwe. P.O. Box B.E 277.Belvedere, Harare, Zimbabwe.

Email: africa.makasi@yahoo.com

\author{
Doi:10.5901/mjss.2014.v5n20p2550
}

Abstract

The research explored factors influencing the adoption of disruptive technologies in the mobile telecommunications industry in Zimbabwe. Data was gathered from the second biggest competitor in the industry with over 3 million subscribers. A survey was conducted by purposively selecting 70 respondents from a population of 3,000,000 (three million) active subscribers from the company's database. A skip interval of 42,857 was used to randomly select the sample. Customer representatives were selected from the company's five regional offices using a two-stage cluster sampling technique. Employee participants were purposively selected from the company's head office. A pilot test was conducted to assess the reliability of the research instrument used. Self-administered questionnaires were used in the research. Research results were collected, recorded and analyzed. All T-tests conducted produced results with $p=0.001$ (which was less than 0.05 at which the tests were conducted) indicating that internal company influences such as staff competence, availability of funding and the type of infrastructure help impede or accelerate the rate of adoption of disruptive technologies in companies. Future research should however look at organizational ambidexterity as well as exploitation and exploration paradigms in organizations in the telecommunications industry and their impact on the adoption of disruptive technologies.

Keywords: disruptive innovation, telecommunications industry, mobile telecommunication.

\section{Introduction}

There is sustained pressure on mobile telecommunication operators to deliver reliable and ubiquitous services to the ever dynamic and complex customer. One way of meeting such expectations is through organizational ambidexterity and unleashing of disruptive technologies. Continued creativity, innovation and product development are key to successful business growth. Since the rate of technology adoption within the organization in Zimbabwe, especially the telecommunications industry is a matter of great concern. This study seeks to explore the reasons behind the slow adoption of disruptive technology. The company under study is one of the fastest growing mobile telecommunications operators in Zimbabwe.

\section{Literature Review}

Sundararajan (2007) asserts that information technology (IT) is very crucial to businesses as it brings about improved productivity and support to business processes. The aforementioned further argued that in mobile communications, IT is central and provides a mediating role, which supports interaction between firms, consumers and customers. Sundararajan (2007) further asserts that mobile telecommunications companies embrace information technology with the aim of improving costs, increasing revenues, improving shareholder value, increasing customer loyalty and satisfaction, 
and reducing business risks and pitfalls. Evans (2004) postulates that technology has become a very important part of the everyday running of a mobile telecommunications business. He further argues that the information technology (IT) businesses are looking for emerging and disruptive technologies that will provide a source of growth and create competitive advantage. Evans (2004) concluded that it is important for mobile telecommunications companies to have insight into disruptive technologies to establish if the technology will create enterprise and value, increase competitive advantage and business agility. However, Kassicieh (2002) is of the opinion that firms are usually more successful when they can embrace disruptive technologies and make them available to their customers.

Sood and Tellis (2010) define technology as a platform based on a unique scientific principle, on which firms manufacture products to serve customers' needs in a given market. The aforementioned argue that technology can be improved by continuous innovations spread over time. According to the authors, innovations can be classified as belonging either to component innovations, or design innovations. They further alluded that as long as the scientific principle remains the same; all these innovations are assigned to the same technology. Sood and Tellis (2010) also highlight that disruptive change requires new strategies, and added that when there is rapid change in conditions, organizations will usually find their former approaches which have led to success in the past, having to no longer be effective. Despite the aforementioned, some researchers such as Moore (2000) argued that it can be hard to let go of old approaches if they have been a source of competitive advantage. Sood and Tellis (2010) assert that many managers think that successful responses to disruptive change are a matter of luck and further clarified the need to craft strategies to best exploit opportunities ahead of the competition. Moore (2000) further indicated that technology itself is not disruptive, what is disruptive is its impact on strategy or business models.

\subsection{Disruptive Technology}

Christensen and Bower (1995, p.10) define disruptive technology as 'innovations that create an entirely new market through the introduction of a new kind of service or product.' Moore (2000) argued that disruptive technology is an innovation that will lead to a totally new way of doing things, how people work and how a firm runs its business. Dhar and Sundararajan (2007) point out that the above definition can be applied to the economic environment where new technologies may influence the entire digital economic environment in an unexpected manner. According to Christensen and Bower (1995), most companies have failed because they did not embrace new technology in their operational framework. Christensen (1995) concluded that disruptive technologies create new challenges and changes to the organization which could be used to the benefit of a mobile telecommunications company. Kassicieh et al. (2002) argued that technologies are there to aid competitive advantage and are not only applied to support the business procedures of a mobile telecommunications company. Kassicieh (2002) defines disruptive technologies as 'discoveries that break through the usual product or technology capabilities and provide a basis for a new competitive paradigm.' The aforementioned researcher further asserts that technologies not only enable a mobile telecommunications company to be more competitive, but also secure more business, produce faster, work better but it also help keep the customer satisfied. Tsui (2001) argued that disruptive technologies have the potential to create new markets, resulting in other industries becoming redundant.

Daneels (2004) defines disruptive technology as a specific type of technological change, operating through a specific mechanism, and has specific consequences. In his research, Daneels (2004) looked critically at the concept of disruptive technology with the aim of establishing when a technology may be deemed as being disruptive. The aforementioned researcher wanted to figure out if disruptiveness is rather implied when new technology is implemented. According to Daneels (2004) disruptive technology is technology that changes the basis of competition by changing the performance metrics along which firms compete. Daneels (2004) further argued that technology on its own is not disruptive, but it only becomes disruptive when it exceeds the performance of the current technology. Jones (2005) postulated that disruptive technology is risky as it challenges current technologies and is difficult to recognize especially in the early development stages. He further maintained that disruptive technology is a threat to market incumbents as market surveys do not always present the new technology as a serious technology that could move successfully into the upper-market. Kaplan (1999) indicated that disruptive technologies are radical innovations or discontinuous innovations, which implies that radical new technology displaces current technology and processes to provide competitive advantage. According to Veryzer (1998) discontinuous innovation is one in which radically new products or technologies involve dramatic leaps in terms of customer familiarity and use. 


\subsection{Theory of Disruptive Technology}

Christensen (2000) argues that understanding sustaining technologies is the basis to understanding the theory of disruptive technologies. Christensen (2000) added that sustaining technologies are those technologies that foster improved product performance. More so Christensen (2000) highlighted that established products can be incremental in nature. Tsui (20001) further points out that sustaining technologies create innovations that are modifications of, or improvements to, or replacements for existing products currently used within a company. Walsh and Kirchhoff (2000) liken the term evolutionary technology to sustaining technology. According to Walsh and Kirchhoff (2000) businesses use information technologies for different purposes within the same firm. These information technologies are updated and enhanced to improve functionality, increase profitability and increase other benefits of the firm.

More so, information technologies provide the mainstream system architecture within a firm Walsh and Kirchhoff (2000), since the aforementioned researchers further argue that enhancing the mainstream information technology implies that the technology is sustained, and further alluded that sustaining technology can be described as successive versions which upgrade the system with improvements to enhance performance that market leaders incorporate into their current systems. Christensen (2000) added that unlike disruptive technologies incremental technologies have a lifecycle of continuous innovations which do not alter markets, but develop information technology in existing products as requested by users. According to Walsh and Kirchhoff (2000), disruptive technology has the characteristic to potentially replace current technologies and discontinue the old ones used in an organization. Clark (2003) noted that the original idea leading to disruptive technology can either rise from the information technology (IT) used for the core competencies within a firm or from exogenous input. Christensen (2000) further commented that the market may pull a product on the market with the effect of simply replacing or providing a substitute for current in-use technology, if the market realizes the potential of a disruptive technology. Walsh and Kirchhoff (2000) highlighted that there is also what is known as sustaining technology and the difference between disruptive technology and sustaining technology is that disruptive technology can result in destroying or replacing a sustaining technology, where as a sustaining technology, on the other hand, will be enhanced with a version upgrade as a result of new or major improvement of the system functionalities.

Walsh and Kirchhoff (2000) indicate that characteristically, evolutionary or sustaining technology has the characteristic to continue as the current 'in-use' technology used by an organization. Jones (2005) comments that if a sustaining technology pushes a product into the market, it is basically the existing technology with new features that will provide a new and major improvement based on the request by the users or the organization. From their model Christensen and Bower (1995) managed to highlight that disruptive technology differs from sustaining technology in the sense that disruptive technology is new and creative and replaces or has the effect of discontinuing current technology, thus making the current technology redundant, therefore, hence destroying the current technology. Walsh and Kirchhoff (2000) posit that sustaining technology entails development of current technologies but on a continuous basis. The result of innovation in terms of sustaining technologies is that the current technologies are better and have added improvements. Walsh and Kirchhoff (2000) concluded that during their research it was difficult to identify a disruptive technology prior to implementation and prior to the use by different users. Hence, it is often difficult to predict what effect disruptive technology will have on the industry and which industry the disruptive technology will enter; thus characteristics of disruptive technology should give insight on how to predict if a new technology will become a disruptive technology.

\subsection{Characteristics of disruptive technologies}

Jones (2005) notes that it is difficult to identify disruptive technology in advance because of its strange characteristics, and disruptive technologies are usually only identified after their effects are known and the benefit is seen with hindsight, as confirmed by Walsh and Kirchhoff (2000). Walsh and Kirchhoff (2000) further assert that disruptive technologies have to mature over a period of time to evolve from an innovation to a useable product. Christensen and Bower (1995) likened disruptive technologies to innovations. However Rayport and Jaworski (2004) disputes that not all innovations are disruptive and they further highlighted the need to look at the different types of innovation so as to understand the characteristics of disruptive technologies. They noted four different types of innovations which include innovation as a user-driven enhancement, innovation as a developer driven development, innovation as a new application or combination of technologies, as well as innovation as technology/market co-evolution. According to Christensen and Bower (1995), these innovations create new industries by developing great solutions. However Christensen (1997) argues that it is important to consider the dynamics of competition between the new and dominant technology so as to be able to appreciate a technological attack when it happens. Roth (2004) commented that when a new technology adopts an upper attack it is referred to as sustaining displacing. 


\subsection{Market structure and technology adoption}

Borzekowski (2009) asserts that firms in communication and information service industries usually market their products using non-linear pricing plans and frequently introduce new generation of services. After empirically assessing market structures' joint effect on technology adoption, Borzekowski (2009), noticed a direct correlation existed between market structures and technology adoption, and noted that there was a concentration speeding up technology adoption and stimulating marketing of the technology. Busse (2000) argues that incumbents in markets with more competitors are more likely to transcend from analogue to digital transmission technologies. This is consistent with cellular subscribers anticipating that significant entry of digital competitors would largely eliminate the market for analogue service. This incentive exceeded that of waiting until the cost of deploying the technology decreased further. Hannan and McDowell (1990) believe that technology adoption has an effect on the market structure. They aforementioned researchers argued that technology adoptions impact on market structure depend upon whether it is the larger or smaller firm within the market that adopts the new technology. According to Hannan (1990), large firm adoptions increase concentration levels and small firm adoptions reduce concentrations. Manyika, et al., (2013) noted that it is very important for an organization operating in an industry which is as dynamic as the telecommunications industry to be able to identify technologies that really matter, thus cementing the importance of organizational ambidexterity. The authors further highlighted that the noise about 'the next big thing' in technological innovations makes it very difficult for organizations to identify which technologies truly matter.

\subsection{Organizational ambidexterity}

According to Raisch and Birkinshaw (2008), organizational ambidexterity is a term used to describe an organizations ability to exploit existing competences as well as explore opportunities. Gupta, Smith and Shalley (2006) concurred that organizational ambidexterity refers to an organization's capability to pursue high levels of exploration and exploitation concurrently, as opposed to managing trade-offs between the two. Tushman and O'Reilly (1996) reveal that there has been a broad agreement that organizational ambidexterity relates to the simultaneous pursuit of exploratory and exploitative activities. In exploring the factors affecting deployment of disruptive technology it is of paramount importance to also consider literature on the dynamic capabilities and resource based view. The theory of dynamic capabilities suggests that an organization can attain a competitive advantage through continuous creation, modification and extending its resource base, while that of the resource based view suggests that an organization with the best unique, inimitable, and non-substitutable set of resources is one that can excel in earning a sustainable competitive advantage against other businesses in its same industry. Teece (1997) suggests that there are three levels of dynamic capabilities, and these include the following:-incremental dynamic capabilities, which are basically those capabilities concerned with continuous improvement of the firm's resource base; renewing dynamic capabilities which are those capabilities that refresh, adapt and augment the resource base; regenerative dynamic capabilities which refers to capabilities that change the way the firm changes its resource base.

Barney (1991) argued that organizations with simultaneously valuable, rare, and non-substitutable and nonimitable resources can be a source of superior performance and thus may enable a firm to achieve sustainable competitive advantage. Teece et al., (1997) also define dynamic capabilities as the capacity to renew competencies so as to achieve congruence with the changing business environment by adapting integrating, and reconfiguring internal and external organizational skills, resources as functional competences. Danneels (2002) argues that it is essential for the resource based view to have a dynamic perspective, so as to understand how firms evolve over time, through their deployment and acquisition of resources. Zahra et al. (2006) also commented that firms must continuously renew and reconfigure themselves if they are to survive. Zollo and Winter (2002) noted that dynamic capabilities are organizational processes or routines which may have become embedded in the firm over time, and are employed to reconfigure the firms resource base by deleting decaying resources or recombining old resources in new ways. Dierickx and Cool (1989) argue that dynamic capabilities are path dependent and are shaped by the decisions the firm has made throughout its history, and the stock of assets that it holds. Helfat and Peteraf (2003) emphasize that to qualify as a dynamic capability, a capability not only needs to change the resource base, but it also needs to be embedded in the firm, and ultimately be repeatable.

\subsection{Organizational Resource Based View}

According to Mwailu and Mercer (1983) the resource-based view is basically a concept that forms the basis of a firm's 
competitive advantage. Wernerfelt, (1984) postulated that the theme lies primarily in the application of a number of tangible and intangible resources of a firm with the aim of transforming a short run competitive advantage into a long run sustainable competitive advantage. Barney (2001) added that to create a sustained competitive advantage a firm needs to have resources that are heterogeneous, unique and non-substitutable.

Exploitation and exploration of disruptive technology paradigms in organizations is a very important phenomenon as was also supported by Dosi (1982). According to Dosi (1982) technologies evolve along certain trajectories which are often punctuated by a discontinuous change that upsets the existing paradigm. Dosi (1982) further alluded that organizations which have built their competencies around an existing paradigm are therefore likely to encounter problems when a new technology is explored. However, Rosenberg (1972) argued Dosi's (1982) assertion and commented that technological change in organizations is inherently path dependent. Rosenberg (1972) further elucidated his assertion by giving an example where he cited Clark (1985) who observed that the early decisions by engineers in the automotive industry to develop the combustion engine instead of the steam or electrical engines affected the decisions by the following generations of engineers. Hence, through path dependency, established firms become increasingly reliant on one particular technology and therefore, are also more vulnerable to changes in the underlying technology.

\subsection{Exploitation and Exploration in organizations}

Levinthal and March (1993) asserts that organizational long term success depends on its ability to exploit current capabilities while at the same time it also explores new competences. In their studies, Levinthal and March (1993) further posits that the trade-off between organizational success and the need to continuously monitor and react according to changes in its external environment are somewhat insurmountable or unavoidable. In agreement, with Levinthal and March (1993), Duncan (1976) argues that ambidextrous organizations are those that are capable of simultaneously exploiting existing competences and exploring new opportunities. However Tushman and O'Reilly (1996) argue that superior performance is a key to organizational ambidexterity.

Many experts have tried to present their views on organizational ambidexterity and the balance between exploitation and exploration. However; according to Raisch et al, (2009) there are several closely interrelated tensions that need to be addressed to enable further research on ambidexterity. Raisch (2009) further pointed one of the tensions as relating to differentiation and integration as alternative or complementary pathways to ambidexterity. In his assertion Raisch (2009) described differentiation as the separation of exploitative and explorative activities into distinct organizational units, and considered integration as the mechanisms that enable organizations to address exploitative and explorative activities within the same organization with the aim of sustained performance. Kaplan (2003) notes that a company's growth agenda rests upon tried and tested strategies, tactics and best practices that are proven to drive results. According to Kaplan (2003), it is therefore very important for organizations through their understanding of innovation lifecycles, to identify the services and technologies that are most vulnerable to competitive disruption and where the greatest opportunities for breakthrough innovation and growth are. More so, the organizational strategies, leadership, structure, processes, and metrics which best support businesses (Kaplan 2003). Christensen (1992) noted that it also paramount to understand the dynamics of an organizations S-Curve as these depict how a product, service or technology evolves over time, hence S-Curves are connected to market adoption which basically results in organizational growth. According to Kaplan (2003) the end of one S-Curve marks the emergence of a new S-Curve, for this reason it is important for organizations to understand such dynamics as it helps them plan to avoid product and service obsolescence and thus promoting growth. Cooper and Smith (1992) echoed that an understanding of where an organizations products, services and technologies fall on the lifecycle can be a key driver to avoiding obsolescence and thus leverage them to the organizational strategic advantage.

\subsection{Why organizations fail to adopt disruptive technologies?}

According to Cooper and Smith (1992) there are reasons why companies fail to identify emerging S-Curve threats and opportunities, and thus fail to adopt disruptive technologies These include,-not focusing on or investing in the new technologies or applications; and not effectively defending an existing business and technology will result in failure to successfully adopt disruptive technology. Walsh and Kirchhoff (2000) also added failure to effectively create new markets and technologies to recreate the business. Christensen (1997) commented that cultural inertia that hinders the ability to play two games at once is also another failure cause as well as lack of Industry foresight, customer Insight, or organizational support.

Kaplan (2003) suggests that there is a close relationship between disruptive technology lifecycles and market 
adoption. In his argument Kaplan 2003) suggested that market adoption reflects a bell curve that tracks to customer/consumer adoption of new technology. According to Barreca (2002) in the innovation lifecycle, there are early adopters, those that are interested in being the first to try to use something before others. Kaplan (2003) also echoes that competitiveness becomes almost entirely based on incremental improvements and economies of scale. Figure 1 summarizes Kaplan's (2003) view point of the market adoption theory.

Figure 1: Innovation Lifecycles and Market Adoption

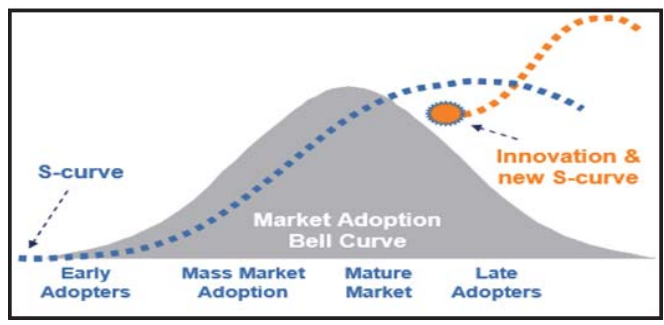

Source: Adapted FromKaplan, 2013

Cooper and Smith (1992) argue that while incremental innovation is important to sustaining revenue growth within an SCurve, jumping S-Curves involves creating or driving disruptive innovations.

\subsection{Market size and technology adoption}

Aghion and Howitt (1992) posit that larger markets facilitate the adoption of more productive disruptive technology by raising the price elasticity of demand for a firm's product. Aghion and Howitt (1992) further remarks that a larger market, either because of population or free trade has increased revenues following the price reduction associated with the introduction of a more productive technology. Technology adoption is more profitable, and the earnings of factor suppliers are less likely to be adversely affected (Walsh and Kirchhoff, 2000). Christensen and Bower (1995) commented that firms operating in larger markets have a greater incentive to adopt more productive technologies, and their factor suppliers have a smaller incentive to resist these adoptions.

In light of the literature reviewed above, this study aims to explore the antecedents of disruptive innovation in the mobile telecommunication industry in Zimbabwe using the methodology described below.

\section{Methodology}

As the main case of study, this study paper reports the findings of gathering data from the second largest competitor in the country with over 3 million subscribers. The survey was conducted by purposively selecting 70 respondents from a population of 3,000,000 (three million) active subscribers from the company's database. A skip interval of 42,857 was used to randomly select the sample. Customer representatives were selected from the company's five regional offices using a two -stage cluster sampling technique.

Using a simple random technique, 14 participants were scientifically drawn from each regional office to make up an overall sample of 70 participants. Employee participants were purposively selected from the company's head office. Selfadministered questionnaires were used in the research. A pilot test was conducted and the assessment of the reliability of the research instruments used in the research performed.

The results of the pilot study were analyzed to test for reliability using SPSS and a Cronbach's alpha value of 0.758 and 0.729 was obtained respectively for the customer and employee questionnaires. The data from the survey were analyzed and presented using a statistical package for social sciences (SPSS).

\section{Results}

Customer and employee responses were analyzed separately, and thereafter the two data sets were combined and analyzed. T-test and One-Way Analysis of Variance (ANOVA) were conducted. Table 1 below shows that the style of 
leadership and its thrust has an impact on the rate of adoption of disruptive technologies, since the vast majority (73.3\%) of the respondents confirmed this. Staff competency, internal organizational systems and availability of funding were also highly rated as very important with $66.7 \%, 53.3 \%$ and $80 \%$ of the respondents respectively indicating so. However, the results also show that infrastructural challenges may also affect the adoption of disruptive technologies as shown on Table 1 below.

Table 1: Factors affecting rate of adoption of disruptive technologies

\begin{tabular}{|l|c|c|c|c|}
\hline Variables & Very Significant & Significant & $\begin{array}{c}\text { Somewhat } \\
\text { Significant }\end{array}$ & Not Significant \\
\hline Style of Leadership and thrust & 73.3 & 26.7 & 0 & 0 \\
\hline Decentralization and Delegation & 40 & 46.7 & 13.3 & 0 \\
\hline Internal Organizational Structure & 40 & 46.7 & 6.7 & 6.7 \\
\hline Staff Competency & 66.7 & 26.7 & 6.7 & 0 \\
\hline Internal organizational systems & 53.3 & 26.7 & 20 & 0 \\
\hline Availability of Funding & 80 & 20 & 0 & 0 \\
\hline Type of infrastructure available & 80 & 20 & 13.3 & 6.7 \\
\hline Environmental Dynamics & 20 & 60 & 13.3 & 6.7 \\
\hline
\end{tabular}

Table 2 shows the results from the T-tests. The results further confirm that the style of leadership and its thrust may help speed up or reduce the adoption of disruptive technologies. This is reflected by the p-value of 0.001 which is less than 0.05. The null hypothesis is thus rejected and the strong relationship between leadership and adoption of disruptive technology is confirmed. Similar results were also obtained with respect to staff competence, availability of funding and the type of infrastructure available as shown on Table 2 below.

Table 2: T Test of Factors Affecting Adoption of Disruptive Technology

\begin{tabular}{|l|c|c|c|c|c|c|}
\hline & \multicolumn{7}{|c|}{ One-Sample Test } \\
\hline & \multirow{2}{*}{$\mathrm{t}$} & \multirow{2}{*}{$\mathrm{Df}$} & \multirow{2}{*}{ Sig. (2-tailed) } & \multirow{2}{*}{ Mean Difference } & \multicolumn{2}{c|}{ 95\% Confidence Interval of the Difference } \\
\cline { 4 - 8 } & & & & & Lower & Upper \\
\hline 1.Style of Leadership and thrust & -8.930 & 29 & .000 & -.733 & -.90 & -.57 \\
\hline 2. Decentralization and Delegation & -2.112 & 29 & .043 & -.267 & -.52 & -.01 \\
\hline 3.Lean Organizational Structure & -1.293 & 29 & .206 & -.200 & -.52 & .12 \\
\hline 4. Staff Competency & -5.288 & 29 & .000 & -.600 & -.83 & -.37 \\
\hline 5.Internal organizational systems & -2.276 & 29 & .030 & -.333 & -.63 & -.03 \\
\hline 6. Availability of Funding & -4.039 & 29 & .000 & -.600 & -.90 & -.30 \\
\hline 7.Type of infrastructure available & -10.770 & 29 & .000 & -.800 & -.95 & -.65 \\
\hline 8. Environmental scanning & .465 & 29 & .645 & .067 & -.23 & .36 \\
\hline
\end{tabular}

\section{Discussion of the Findings}

Research results have confirmed that for companies to be able to fully adopt disruptive technologies, there is need for a staff competency assessment within the organization. This may entail promoting and developing innovation and creativity within the workforce. This internal process breeds intra-preneurship; a prerequisite for the adoption of disruptive technologies. In their studies, Levinthal and March (1993) further posits that the trade-off between organizational success and the need to continuously monitor and react according to changes in its external environment are somewhat insurmountable or unavoidable. Analysis of business environment helps to identify strength weakness, opportunities and threats. Thus, a SWOT analysis is necessary for the survival and growth of every business enterprise.

Most of the respondents (87\%), commented that quality of network is very fundamental in driving successful disruptive technologies. Teece et al., (1997) recommends the use of dynamic capabilities to renew competencies so as to achieve congruence with the changing business environment by adapting integrating, and reconfiguring internal and external organizational skills, resources as functional competences.

Literature (Teece et al., 1997; Kaplan, 2003; Raisch, 2009) supports the view that organizations with unique, difficult to copy, and inimitable resources can create a very strong competitive advantage against its rivalry's if it makes 
use of its available resources. Our paper however concluded that the exploration and exploitation environment demands that disruptive technologies are strategically deployed in compliance with the changes in the business environment. In order to drive this process, internal company influences such as staff competence, availability of funding and the type of infrastructure help impede or accelerate the rate of adoption of disruptive technologies in companies.

\section{Conclusions}

Based on the research findings, it was concluded that centralization hamstrings the organization's capacity to adopt disruptive technologies. Decision making within such organizations takes long and for this reason adoption of disruptive technologies was found lagging behind. Besides the critical role of staff competency (a prerequisite, especially in this industry), a plethora of other contributing factors which include availability of funding, type of infrastructure available, leadership orientation, and nature of promotional campaigns also contribute to the faster adoption of disruptive technologies. With respect to leadership, it was concluded that style of leadership and its thrust has a direct impact on the adoption of disruptive technologies. Leadership styles which promote the creativity and innovation among the employees are critical to the successful adoption of disruptive innovation. Adoption of disruptive technologies is highly capital intensive; thus for any company to successfully manage this adoption it must be financially stable. This is in line with the theory of dynamic capabilities which suggests that an organization can attain a competitive advantage through continuous creation, modification and extending its resource base, while that of resource based view suggests that an organization with the best unique, inimitable, and non-substitutable set of resources is one that can excel in earning a sustainable competitive advantage against other businesses in its same industry.

\section{References}

Aghion, P., and Howitt, W.P., (1992). A Model of Growth through Creative Destruction. Econometrica. 60, 323-351.

Barney, J. B., (1986). Organizational culture: can it be a source of sustained competitive advantage? Academy of Management Review, $11(3), 656-665$.

Barney, J. B., (1991). Firm resources and sustained competitive advantage. Journal of Management, 17(1), 99-120.

Barney, J. B., (2001a). Is the resource-based view a useful perspective for strategic management research? Yes. Academy of Management Review; 26 (1), 41-56.

Barreca, H., (2002). The Entrepreneur's Internet Handbook: Your Legal and Practical Guide to Starting a Business. Sphinx Publishing, USA.

Barney, J. B., (2001b). Resource-based theories of competitive advantage: a ten year retrospective on the resource-based view. Journal of Management, 27, 643-650.

Bessant, J., and Caffyn, S., (1997). High-involvement innovation through continuous improvement. International Journal of Technology Management, 14, 7-28.

Borzekowski, R., (2009). The Effect of Market Structure on Cellular Technology Adoption and Pricing. Quantitative Marketing and Economics, 7, 147-179

Bower, J. L., and Christensen, C. M., (1995). Disruptive Technologies: Catching the Wave. Harvard Business Review, 73(1): 43-53.

Clark, P., (2003). Organizational innovations. London: Sage Publications.

Cooper, A.C., and Smith, C.G., (1992). How established firms respond to threatening technologies. The Academy of Management Executive, 6 (2), 56-69.

Dierickx, I., and Cool, K., (1989). Asset stock accumulation and sustainability of Competitive advantage, Management Science, 35, 1504-1511.

Christensen, C.M., (2000). The innovators dilemma. New York: Haper Collins Publishers

Christensen, C.M., and Overdorf, M., (2000).Meeting the challenge of disruptive change. Harvard Business Review, 78 (2), 66-76.

Dosi,G., (1982). Technological paradigms and technological trajectories: Research Policy, 11(3), 147-162.

Danneels, E., (2004). Disruptive technology reconsidered: a critique and research agenda. Journal of Product Innovation Management, 21(4), 246-258.

Dhar, V. and Sundararajan, A., (2007). Information Technologies in Business: A Blueprint for Education and Research. Information Systems Research, 18(2), 125-141.

Duncan, R.B., (1972). Characteristics of organizational environments and perceived environmental uncertainty. Administrative Science Quarterly, 20, 613-629.

Duncan, C. and Howitt, D., (2004). Response rate. The SAGE Dictionary of Statistics

Evans A, (2004). Technology in Action. In: Technology in Action. Addison-Wesley.

Gupta, A. K., Smith, K. G., and Shalley, C. E., (2006). The interplay between exploration and exploitation. Academy of Management Journal, 49(4), 693-706.

Helfat, C. E., and Peteraf, M., (2003). The dynamic resource-based view: capability lifecycles. Strategic Management Journal, 24, 9971010. 
Helfat, C. E., Teece, D., and Winter, S., (2007). Dynamic Capabilities: Understanding Strategic Change in Organizations. Blackwell, London.

Jones, R., (2005). Disruptive Technology: recognizing and coping with the inevitable. Metalworking Production Annual review. Metalworking Production Annual review, 149 (2004/5), 19-20.

Kaplan, S.M., (1999). Discontinuous Innovation and the growth paradox. Strategy and leadership, 27, (2), 16-21.

Kassicieh, S.K, Walsh and Kirchhoff, B.A., (2002). The role of small firms in the transfer of disruptive technologies. Technovation, 22(2), 667-674.

Kotler, P., (2003). Marketing Management: 1th ed., Prentice-Hall International Editions, Englewood Cliffs, NJ.

Lewis, M. W., 2000. Exploring paradox: Toward a more comprehensive guide. Academy of Management Review, 25, 760-776.

Levinthal, A. and March, G., (1993). The Myopia of Learning. Strategic Management Journal, 14, 95-112.

Manyika, J.; Chui, M; Bughin, J; Dobbs, R; Bisson, P and Marrs, A., (2013). Disruptive technologies: Advances that will transform life, business, and the global economy. McKinsey Global Institute.

Majumdar, S. and Venkataraman, S., (1998). Network Effects and the Adoption of New technology: Evidence from the U.S. Telecommunications Industry. Strategic Management Journal, 19, 1045-1062.

Moore, G., (2000). Living on the fault line. New York: Harper Business.

Paul, W.G., (2005). Dictionary of Statistics \& Methodology, Third Edition:

Porter, M.E., (1998). Competitive Advantage: Creating and Sustaining Superior Performance, with a new introduction. New York: Free Press.

Raisch, S., \& Hotz, F., (2008). Shaping the context for learning: Corporate alignment initiatives, environmental munificence, and firm performance. In S. Wall, C. Zimmermann, R. Klingebiel, \& D. Lange (Eds.), Strategic reconfigurations: Building dynamic capabilities in rapid-innovation-based industries.

Rayport, J., and Jaworski, B. (2004). Introduction to e-commerce. 2nd Ed. New York: McGraw-hill.

Rogers, E., (1963). Diffusion of innovation. 3rd edition. In: Diffusion of innovation 3rd edition. New York Press.

Robinson, C., (2011). Real world Research. In: Real world Research: Wiley.

Rosenberg, N., (1972). Technology and American economic growth: Google Books

Teece, D., (1997). Dynamic capabilities and strategic management. Strategic Management Journal, 18, 509-533.

Schmidt, G., and Druehl, C., (2008). When is a disruptive innovation disruptive? Journal of Product Innovation Management, 25(4), 110120.

Sood, A., and Tellis, G., (2010). Demystifying disruption: A new model for understanding and predicting disruptive technologies. Marketing Science working paper number 10-102.

Sundararajan, A., and Dhar, V., (2007). Information Technologies in Business: A Blueprint for Education and Research. Information Systems Research, 18(2), 125-141.

Tsui, A. S., Meyer, A. D. \& Hinings, C. R., (1993). Configurational approaches to organizational analysis. Academy of Management Journal, 36, 1175-1195.

Tushman, M. L. and O'Reilly, C. A., (1996). Managing evolutionary and revolutionary change. California Management Review, 38, 8-30.

Tushman, M., (1985). Organizational evolution: a metamorphosis model of convergence and reorientation. Research in Organizational Behavior, 171-122.

Veryzer, R., (1998). Radical Innovation. In: Radical Innovation. Boston, MA: Harvard business School Press.

Walsh, S. and Linton, J., (2000). Infrastructure for Emerging Markets Based on Discontinuous Innovations. Engineering Management Journal, 12(2), 23-31.

Wernerfelt, B., (1984). Resource-Based Theory: Creating and Sustaining Competitive Advantage. Strategic Management Journal, 5 (2), 171-180.

Zahra, S., H., and Davidsson, P., (2006).Entrepreneurship and dynamic capabilities: a review, model and research agenda. Journal of Management Studies, 43, 917-955.

Zollo, M. and Winter, S., (2002). Deliberate learning and the evolution of dynamic capabilities. Organization Science, 13, 339-351. 